\title{
Design de SPS: Por onde andamos? Uma análise sistemática das publicações recentes do P\&D Design
}

\author{
PSS Design: Where are we going? A systematic analyse of P\&D Design recent \\ publications.
}

GALLINA, Gabriel; Mestre em Design. Centro Universitário FADERGS.

arq.gallina@gmail.com

CAMPELO, Filipe; Doutor em Administração. Universidade do Vale do Rio dos Sinos. fcampelo@unisinos.br

\section{Resumo}

Sistema produto-serviço é um assunto bastante discutido em diversas áreas, e ganha especial relevância frente a sua importância no contexto do Design. Este artigo se propõe a levantar como o tema vem sendo abordado no meio acadêmico a partir de uma análise sistemática dos artigos publicados entre 2010 e 2016 nos anais do P\&D Design - Congresso Brasileiro de Pesquisa e Desenvolvimento em Design. Este processo possibilita discutir o teor das publicações frente aos eixos conceituais de SPS, e permite, também, estabelecer um panorama quantitativo e qualitativo sobre por onde transita o tema no contexto da pesquisa. Diante dos achados, o artigo traz uma reflexão sobre causas e reflexos da produção acadêmica nacional sobre o Design de SPS.

Palavras Chave: Design de sistema produto-serviço; Análise sistemática; P\&D Design.

\begin{abstract}
Product-services system is a exhaustive discuss subject at different areas, and receive special attention because your design content importance. This article is proposed to raised how the theme is been treated in academia from a systematic analysis of P\&D Design (Brazilian Congress of Design Research and Development) articles between 2010 and 2016. This process makes it possible to discuss the content of the publications in front of the conceptual axes of PSS, and also allows to establish a quantitative and qualitative view about where the subject transits in the context of the research. The article discuss about causes and reflections of the national academic production about PSS Design.
\end{abstract}

Key-words: PSS Design; Systematic analyse; P\&D Design. 


\section{Introdução}

Diversas organizações estão atentas para a elaboração de uma oferta conjunta de bens materiais e imateriais, promovendo a integração de ambos para atingir resultados mais competitivos no mercado e completos para o usuário (MANZINI, 1990). Neste sentido, o Sistema Produto-Serviço (SPS) é reconhecido como um modelo de solução que combina aspectos tangíveis e intangíveis para uma oferta conceitualmente diferenciada, considerando o ciclo de vida completo deste sistema, o consumo sustentável de seus recursos, a otimização da produção e a redução de impactos no meio-ambiente.

o Design de SPS é uma abordagem predominantemente estratégica, que desloca o foco da atividade de projetar artefatos para a organização de um sistema eficiente de produtos e serviços que, conjuntamente, atendem às necessidades do usuário através de uma entrega mais abrangente e qualificada. (CELASCHI; DESERTI, 2007). O contexto internacional nos mostra que este assunto já alcançou a maturidade em países desenvolvidos, estando a aplicação do Design de SPS incorporada nas suas culturas através da implementação de programas que introduzem novos paradigmas de produção e consumo. Já no cenário nacional, autores como Vezzoli (2018) apontam para um quadro bastante promissor e efervescente.

Entretanto, se por um lado estes autores identificam uma perspectiva positiva, também identificam que, no Brasil, faltam competências mínimas para o desenvolvimento deste tipo de solução. Isso porque nossas instituições de ensino superior não habilitam devidamente o acadêmico para elaborar este tipo de projeto, o que, por consequência, resulta em profissionais que não sabem atuar neste segmento de maneira qualificada. Logo, entendemos que é relevante traçarmos um panorama do que vem sendo elaborado e discutido sobre Design de SPS no país. Para isso tomamos como base a produção de um dos maiores eventos nacionais em pesquisa e desenvolvimento em design, o P\&D Design - Congresso Brasileiro de Pesquisa e Desenvolvimento em Design. Através de uma análise sistemática de seus anais desde 2010, reunimos estudos semelhantes para uma avaliação crítica e meta-analítica sobre o tema, propiciando uma síntese fundamentada em critérios objetivos e previamente definidos. Assim, o recorte desta pesquisa busca levantar quantitativa e qualitativamente o que vem sendo investigado sobre Design de SPS no contexto acadêmico nacional.

Este artigo parte de uma breve contextualização sobre SPS, para, em um segundo momento, trazer um levantamento da produção acadêmica nas 9a , 10aㅡ, 11a e 12a edições do P\&D Design. Ao final, se discute sobre os achados e se faz uma breve reflexão a respeito da situação e da relevância deste tema para o cenário nacional de pesquisa.

\section{SPS: Conceito, definições e abordagens}

O desenvolvimento de um SPS representa um grande desafio por alterar o foco das atividades que envolvem o produto ou serviço isolado, privilegiando a orquestração de um sistema de componentes. Um produto pode ser entendido como o resultado tangível de um processo de manufatura, dotado de alguma função, utilidade ou significado para seus usuários (KRIPPENDORF, 2005). Já um serviço pode ser descrito a partir de três características distintas: é intangível, heterogêneo e inseparável. Intangível pois considera performances, e não um objeto que pode ser 
contado, metido, inventariado, testado ou verificado antes de ser adquirido. Heterogêneo pois sua performance é variável de fornecedor para fornecedor, de usuário para usuário, de dia para dia. Inseparável pois a produção e o consumo de um serviço acontecem de forma simultânea, envolvendo, inclusive, interação entre usuário e o fornecedor do serviço. (PARASURAMAN, 1985).

Historicamente, a primeira definição formal de SPS foi dada em 1999 por Goedkoop et al. em sua publicação Product service systems, ecological and economic basics, justificando sua elaboração através de aspectos relacionados ao baixo impacto ambiental e alta competitividade. Para estes autores, "O SPS é um conjunto de produtos e serviços comercializáveis capazes de satisfazer conjuntamente a necessidade dos clientes. " (GOEDKOOP et al, 1999, p.18). É importante observar que várias definições para este mesmo conceito surgiram nas últimas décadas. Esta diversidade é decorrente das distintas ênfases e prioridades abordadas por seus autores, que as fundamentam a partir dos diferentes contextos onde se insere o SPS, como administração, engenharias, tecnologia da informação, e design (Quadro 1).

Quadro 1. Algumas definições de SPS

\begin{tabular}{|c|c|c|}
\hline Autor & Data & Definição \\
\hline $\begin{array}{l}\text { Goedkoop } \\
\text { et al }\end{array}$ & 1999 & $\begin{array}{l}\text { SPS é um conjunto de produtos e serviços comercializáveis capazes de satisfazer conjuntamente } \\
\text { a necessidade dos clientes. [...] O SPS pode trazer benefícios ao ambiente na conexão com a } \\
\text { criação de um (novo) negócio. }\end{array}$ \\
\hline Mont & 2001 & $\begin{array}{l}\text { SPS pode ser definido como um sistema de produtos, serviços, redes de suporte e infraestrutura } \\
\text { desenhado para ser: competitivo, satisfazer as necessidades do usuário e clientes, ter um baixo } \\
\text { impacto ambiental se comparado a modelos tradicionais de negócio. }\end{array}$ \\
\hline $\begin{array}{l}\text { Tukker e } \\
\text { Tischner }\end{array}$ & 2006 & $\begin{array}{l}\text { SPS é um sistema de produtos, serviços e infraestrutura que lida de maneira conjunta com as } \\
\text { necessidades e exigências dos clientes de maneira mais eficiente, trazendo mais valor para } \\
\text { ambos os lados (empresa e cliente) em comparação com uma oferta isolada de um produto [...]. } \\
\text { SPS pode criar valor a partir do consumo de materiais e energia, reduzindo o impacto ambiental } \\
\text { significativamente no ciclo de vida de sistemas mais tradicionais }\end{array}$ \\
\hline Baines et al & 2007 & $\begin{array}{l}\text { SPS é uma oferta integrada de produto e serviço que fornece valor. O SPS oferece a } \\
\text { oportunidade de dissociar o sucesso económico do consumo material e, assim, reduzir o } \\
\text { impacto ambiental da atividade econômica. }\end{array}$ \\
\hline $\begin{array}{l}\text { Manzini e } \\
\text { Vezzoli }\end{array}$ & 2002 & $\begin{array}{l}\text { SPS é o resultado de uma estratégia inovadora que desloca o centro do negócio e venda isolada } \\
\text { de produtos (físicos) para um sistema que oferece produtos e serviços que, juntos, são capazes } \\
\text { de satisfazer uma determinada demanda. }\end{array}$ \\
\hline Tukker & 2003 & $\begin{array}{l}\text { SPS consiste numa combinação de produtos tangíveis e serviços intangíveis concebidos e } \\
\text { combinados de forma a que sejam conjuntamente capazes de satisfazer as necessidades dos } \\
\text { clientes finais. }\end{array}$ \\
\hline $\begin{array}{l}\text { Celaschi e } \\
\text { Deserti }\end{array}$ & 2007 & $\begin{array}{l}\text { Ao processo de sinergia entre produto, sua comunicação e a maneira como este chega ao } \\
\text { consumidor final chamamos Sistema Prodotto, termo que considera em sua centralidade o } \\
\text { significado resultante da relação entre os componentes de uma oferta. }\end{array}$ \\
\hline Meroni & 2008 & $\begin{array}{l}\text { SPS é uma mistura de produtos, serviços, comunicação e pessoas; quando concebido para } \\
\text { responder a uma necessidade específica, é o que chamamos de solução. O design estratégico do } \\
\text { SPS muda o foco da inovação de produto ou design de serviço para uma estratégia integrada de } \\
\text { design de produto-serviço, orientado para produzir soluções. }\end{array}$ \\
\hline Zurlo & 2010 & $\begin{array}{l}\text { (...) um sistema-produto, isto é, o conjunto orgânico e coerente dos vários meios (produto, } \\
\text { serviço, comunicação) com os quais a empresa constrói a própria identidade, posiciona-se no } \\
\text { mercado, define o sentido de sua missão na sociedade. (...) O efeito de sentido, em outras } \\
\text { palavras, não apresenta somente novos significados (...), mas se realiza na dimensão sistêmica } \\
\text { da oferta. }\end{array}$ \\
\hline
\end{tabular}

Fonte: Os autores 
A partir das abordagens aqui relacionadas, podemos observar a diversidade que envolve a discussão sobre SPS. Este panorama permite identificar duas abordagens amplas e mais organizadas sobre o assunto: o SPS focado na produção eficiente e sustentável, e o SPS focado no desenvolvimento de redes de atores, considerando a solução como um resultado social. (COSTA et al, 2018). A primeira abordagem está mais relacionada com autores ligados à engenharia de produção, e traz um conceito de SPS pautado pela sustentabilidade e atento à competitividade. Esta perspectiva considera aspectos como a redução de impactos ambientais, eficiência operacional, ciclo de vida do sistema, otimização de processos e produção. (GOEDKOOP et al, 1999; MONT, 2001; BAINES et al, 2007, TUKKER; TISCHNER, 2006).

Já a segunda abordagem define o SPS pela perspectiva estratégica, focando na elaboração de uma solução completa e que satisfaça o usuário final. Por este viés, o foco recai no sistema e na relação entre seus componentes, para entregar, também, uma ideia de sentido e significado. (MANZINI; VEZZOLI, 2002; MERONI, 2008; TUKKER, 2003; ZURLO, 2010; CELASCHI; DESERTI, 2007).

É possível sugerir, portanto, que os achados desta pesquisa nos anais do P\&D Design estejam alinhados com alguma destas abordagens. Esta averiguação poderá nos apontar para que lado caminha a pesquisa sobre Design de SPS no contexto nacional. A seguir, apresentamos o método utilizado para esta pesquisa, seu delineamento e resultados.

\section{0 método}

A condução desta pesquisa está baseada em uma revisão elaborada de maneira sistemática. Este método se apresenta como o meio mais adequado para identificar, avaliar e interpretar dados disponíveis e relevantes sobre um determinado tema de interesse (KAHN et al, 2003).

\subsection{Delineamento da pesquisa}

A pesquisa foi estruturada com o objetivo de identificar os artigos que abordam o tema SPS no campo do Design. Para isso, definimos como base investigativa os anais do P\&D - Congresso de Pesquisa e Desenvolvimento em Design, um dos mais importantes eventos acadêmicos do Brasil e maior congresso da América Latina na área do Design. Este evento bianual é voltado para a discussão da pesquisa e do ensino de design, sendo considerado um importante fórum para divulgação e disseminação do conhecimento científico e aplicado. Assim, nossos critérios de busca foram:

a) Fonte: Anais publicados das edições 9a $(2010)^{1}, 10^{a}(2012)^{2}, 11^{\text {a }}(2014)^{3}$ e $12^{\text {a }}(2016)^{4}$ do Congresso P\&D Design;

b) Ocorrência das palavras 'SPS', 'Sistema produto', 'Sistema produto serviço', 'Sistema produto-serviço', 'Sistemas produtos serviços', 'Sistemas produtos-serviços', 'PSS',

\footnotetext{
${ }^{1}$ Disponível em https://www.dropbox.com/sh/89jl1pismsnq9u0/AAAZwuH0TqrgAsYQbCtl-43Ta?dl=0

${ }^{2}$ Disponível em http://www.peddesign2012.ufma.br/anais/

${ }^{3}$ Disponível em https://www.proceedings.blucher.com.br/article-list/11ped-233/list\#articles

${ }^{4}$ Disponível em http://www.proceedings.blucher.com.br/article-list/ped2016-277/list\#articles
} 
'Product-service system', 'Product-service systems' e 'Products and service systems' em busca direta nos títulos e palavras-chave.

c) Período de tempo: 6 anos, de 2010 até 2016.

O percurso desta pesquisa é ilustrado de maneira resumida no Quadro 2, em que as etapas investigativas estão relacionadas aos cinco passos sugeridos por Kahn et al (2003). O primeiro passo a ser feito é Enquadrar a questão, onde o problema abordado deve, antes do início da revisão, estar especificado de maneira clara e inequívoca. Este procedimento inicial possibilita que a revisão mereça confiabilidade, permitindo que a mesma seja auditada, reproduzida, continuada ou ampliada.

O segundo passo requer Identificar publicações relevantes. O critério de seleção destes documentos deve vir diretamente das definições elaboradas no passo anterior. Os motivos para inclusão e exclusão devem ser registrados, justificando sua pertinência para com o estudo proposto.

O terceiro passo sugere Acessar estudos de qualidade, em que deve ser feita uma avaliação aprofundada e refinada dos achados. Este tipo de avaliação detalhada da qualidade será utilizado para explorar a heterogeneidade da amostra.

O quarto passo recomenda Resumir das evidências. A síntese de dados consiste na tabulação das características da pesquisa, suas qualidades e efeitos. Este processo compreende, também, a aplicação de métodos estatísticos para explorar diferenças e estabelecer possíveis combinações meta-analíticas. Deve-se planejar antecipadamente que tipo de exploração será feita diante da heterogeneidade coletada. Os achados devem ser organizados de maneira descritiva.

O quinto e último passo corresponde a Interpretar os achados, em que se explora vieses e se propõe relações entre diferentes publicações.

Quadro 2. O percurso desta revisão sistemática

\begin{tabular}{|c|c|c|}
\hline Etapa investigativa & Descrição & Critério \\
\hline \multirow{3}{*}{ 1. Enquadrar a questão } & Definição do tema de pesquisa & Design de SPS \\
\hline & $\begin{array}{l}\text { Levantamento de palavras- } \\
\text { chave }\end{array}$ & $\begin{array}{l}\text { sps, sistema produto, sistema produto serviço, } \\
\text { sistema produto-serviço, sistemas produtos serviços, } \\
\text { sistemas produtos-serviços, pss, product-service } \\
\text { system, product-service systems, product and } \\
\text { service system }\end{array}$ \\
\hline & Definição do intervalo de tempo & 2010 a 2016 \\
\hline 2. Identificar publicações & Escolha da base de dados & $\begin{array}{l}\text { Anais dos Congressos P\&D Pesquisa e } \\
\text { Desenvolvimento em Design }\end{array}$ \\
\hline \multirow{2}{*}{$\begin{array}{l}\text { 3. Acessar estudos de } \\
\text { qualidade }\end{array}$} & Pesquisa na base de dados & Artigos completos publicados \\
\hline & Importação dos artigos & Download dos artigos \\
\hline 4. Resumir as evidências & Planilhamento dos artigos & Organização em Microsoft Excel \\
\hline 5. Interpretar os achados & Análise dos resultados & Leitura completa dos artigos \\
\hline
\end{tabular}


O resultado desta busca apontou para nove publicações, conforme os critérios aqui definidos. Todos os artigos estavam disponíveis online em formato PDF e foram coletados manualmente. O processo de resumo do banco de dados se deu inicialmente com o acesso a cada um dos artigos para a transposição de suas informações em uma planilha geral. Esta planilha foi o principal instrumento utilizado pelos autores para apoio da análise, e compreendia a seguinte relação de dados de cada artigo: Edição do congresso; Ano do congresso; Categoria; Título; Resumo; Palavras-chave; Objetivo do artigo; Autor; e Instituição de ensino de origem. Os resultados serão apresentados e discutidos na próxima seção.

\section{Análise e discussão dos resultados: As publicações sobre SPS no P\&D Design}

A primeira verificação traz um panorama do volume total de publicações em anais do $P \& D$ neste período de tempo. Da 9a edição (2010) até a mais recente, 12a (2016), temos um total de 2172 publicações em anais, sendo que, destes, apenas nove artigos se referem ao assunto SPS. A Tabela 1 nos mostra esta relação e diz, também, qual é a representatividade do tema diante do total de publicações para cada período.

Tabela 1 - Publicações sobre SPS nos anais do P\&D Design, por edição

\begin{tabular}{ccccc}
\hline Edição & Ano & $\begin{array}{c}\text { Publicações } \\
\text { nos Anais }\end{array}$ & $\begin{array}{c}\text { Artigos } \\
\text { sobre SPS }\end{array}$ & $\%$ \\
\hline 12 & 2016 & 521 & 1 & 0,19 \\
11 & 2014 & 322 & 0 & 0 \\
10 & 2012 & 800 & 4 & 0,5 \\
$\mathbf{9}$ & 2010 & 529 & 4 & 0,75 \\
\hline & & 2172 & 9 & $0,41 \%$ \\
\hline
\end{tabular}

Fonte: Os autores

A análise desta primeira tabela nos diz que artigos sobre SPS atendem a somente $0,41 \%$ da soma total de publicações deste congresso no período de 2010 a 2016. Podemos observar que 2010 e 2012 foram anos em que o assunto teve maior representatividade, contabilizando 4 artigos para cada um destes anos e perfazendo $88,8 \%$ sob seu total. Também verificamos que a edição de 2014 não trouxe nenhum artigo sobre o assunto, e que em 2016 tivemos apenas um exemplar.

Foi possível identificar nesta amostra de nove publicações um total de dezenove palavraschave diferentes. Após coletar este item de cada um dos artigos e inseri-lo na planilha, observamos pela sua quantificação quais assuntos estão mais ou menos associados ao termo de busca de nossa pesquisa (Tabela 2). Este movimento traz pistas do contexto de pesquisa que mais vem se aproximando do SPS no universo do Design. 
Tabela 2: Palavras-chave utilizadas nos artigos sobre SPS

\begin{tabular}{lcc}
\hline \multicolumn{1}{c}{ Palavra-chave } & Quantidade & \% \\
\hline Sistema Produto Serviço ${ }^{5}$ & 8 & 28,6 \\
Sustentabilidade & 2 & 7,1 \\
Design para sustentabilidade & 2 & 7,1 \\
Água de chuva & 1 & 3,6 \\
Análise de concerns & 1 & 3,6 \\
Brechós & 1 & 3,6 \\
Colaboração & 1 & 3,6 \\
Coleta seletiva & 1 & 3,6 \\
Customização em Massa & 1 & 3,6 \\
Design & 1 & 3,6 \\
Design de Sistemas Produto/Serviço & 1 & 3,6 \\
Design estratégico & 1 & 3,6 \\
Design para experiência & 1 & 3,6 \\
Experiência do usuário & 1 & 3,6 \\
Móveis-estofados & 1 & 3,6 \\
Paradas de ônibus & 1 & 3,6 \\
Produtos de moda & 1 & 3,6 \\
Resíduos & 1 & 3,6 \\
Teoria dos appraisals & 1 & 3,6 \\
& & \\
\hline & 28 & 100 \\
\hline
\end{tabular}

Fonte: Os autores

Entre as dezenove palavras-chave identificadas destacam-se três que representam $42,8 \%$ da sua totalidade. Aquela que desponta é Sistema produto serviço, com oito ocorrências, representando $28,6 \%$ do total de palavras-chave. Em seguida temos Sustentabilidade e Design para sustentabilidade, que representam $7,1 \%$ cada. Se entendermos que o primeiro é um termo genérico e que remete ao próprio tema, temos na sustentabilidade o viés mais presente no contexto destas publicações levantadas, com $14,2 \%$ de representatividade.

O processo de análise de dados também nos permitiu elaborar um levantamento da origem dos nove artigos (Tabela 3). Ao fazer isso, conseguimos ter um panorama global a respeito de que lugar vem as contribuições sobre SPS para este congresso.

\footnotetext{
${ }^{5}$ As variações deste termo foram reunidas aqui em um conceito único
} 
Tabela 3: Instituições de origem dos artigos sobre SPS

\begin{tabular}{lccc}
\hline \multicolumn{1}{c}{ Instituição de Ensino } & Estado & Quantidade & $\%$ \\
\hline Universidade Federal do Paraná & PR & 3 & 33,3 \\
Universidade do Vale do Rio dos Sinos & RS & 2 & 22,2 \\
Universidade Federal de Campina Grande & PB & 1 & 11,1 \\
Universidade do Estado de Minas Gerais & MG & 1 & 11,1 \\
Universidade Federal da Bahia & BA & 1 & 11,1 \\
Universidade Positivo & PR & 1 & 11,1 \\
\hline & & 9 & 100
\end{tabular}

Fonte: Os autores

Ao analisarmos por estado, a maior contribuição vem do Paraná, com três publicações, e Rio Grande do Sul, com duas publicações. As instituições de ensino mais representativas nesta pesquisa foram Universidade Federal do Paraná, com três publicações, e Universidade do Vale do Rio dos Sinos, com duas publicações, somando $55,5 \%$ do total da frequência. Este destaque provocou uma investigação paralela para verificar se o foco destes dois PPGs sugere um alinhamento conceitual com o tema SPS. Neste sentido, constatamos que o Programa de Pós-Graduação em Design da UFPR tem como uma de suas linhas de pesquisa Sistemas de Produção e Utilização, em que

(...) busca o desenvolvimento de conhecimento de maneira a se obter design economicamente viável, socialmente justo e ambientalmente responsável, conferindo maior competitividade ao setor produtivo, desde associações de artesãos até grandes empresas. Esta linha vem desenvolvendo critérios, ferramentas, métodos e reflexões críticas, contribuindo para o aperfeiçoamento da teoria e prática do Design de produtos, serviços e sistemas. (Universidade Federal do Paraná, 2018).

Já o PPG em Design da Unisinos apresenta foco em Design Estratégico, justificando que

\begin{abstract}
Esse foco se caracteriza por investigar a área de Design na perspectiva de contexto e inovação dos bens de uso em toda a cadeia de valor, para, desse modo, definir estratégias de desenvolvimento sustentável, orientadas ao Design. A ênfase do Programa é o estudo das estratégias elaboradas pelo Design para orientar a ação projetual e, sobretudo, a ação organizacional em direção à inovação e à sustentabilidade. Essas estratégias são elaboradas pelo Design em um processo que envolve todo o seu ecossistema de atuação: o meio organizacional (escritórios de design, empresas e demais organizações), o mercado, a sociedade e o meio-ambiente. Assim, o processo de design é considerado e desenvolvido no âmbito das multíplices relações instauradas na ação projetual, com implicações metodológicas relevantes. O enfoque do Design Estratégico desloca-se do processo de design em si para o conjunto de relações que esses ecossistemas entre si desenvolvem. (Universidade do Vale do Rio dos Sinos, 2018).
\end{abstract}

Ao olharmos para a área de concentração de pesquisa dos programas de mestrado e doutorado destas duas instituições, notamos que existe sim um alinhamento conceitual, o que justificaria possivelmente sua maior incidência na produção de artigos sobre o tema. 
Partindo para uma análise qualitativa destas publicações, foi possível identificar o objetivo pretendido em cada artigo (Quadro 3).

Quadro 3. Análise qualitativa dos achados

\begin{tabular}{|c|c|c|c|c|}
\hline Edição & Título & Palavras-chave & Autor & IES \\
\hline $12^{\mathrm{a}}$ & $\begin{array}{l}\text { Perfil de concerns e projeto } \\
\text { de sistemas produtos- } \\
\text { serviços na gastronomia: } \\
\text { uma discussão metodológica }\end{array}$ & $\begin{array}{l}\text { Experiência do usuário; } \\
\text { Sistema produto-serviço; } \\
\text { Teoria dos appraisals; Análise } \\
\text { de concerns }\end{array}$ & $\begin{array}{l}\text { HIRANO, C. B. O; } \\
\text { COSTA, F.C.X. }\end{array}$ & $\begin{array}{l}\text { Universidade } \\
\text { do Vale do } \\
\text { Rio dos Sinos }\end{array}$ \\
\hline $10^{\mathrm{a}}$ & $\begin{array}{l}\text { Lixo sustentável: uma } \\
\text { proposta de SPS para coleta } \\
\text { do lixo urbano }\end{array}$ & $\begin{array}{l}\text { Sustentabilidade; Sistema } \\
\text { Produto-Serviço; Coleta } \\
\text { seletiva }\end{array}$ & $\begin{array}{l}\text { ARRUDA, A.; } \\
\text { ARRUDA, F. O. }\end{array}$ & $\begin{array}{l}\text { Universidade } \\
\text { Federal de } \\
\text { Campina } \\
\text { Grande } \\
\end{array}$ \\
\hline $10^{\mathrm{a}}$ & $\begin{array}{l}\text { A Colaboração no Nível } \\
\text { Estratégico como Facilitador } \\
\text { no Design de Sistemas } \\
\text { Produto-Serviço }\end{array}$ & $\begin{array}{l}\text { Colaboração; design; Sistema } \\
\text { produto-serviço e estratégico. }\end{array}$ & $\begin{array}{l}\text { FONTANA, I. M.; } \\
\text { HEEMANN, A.; } \\
\text { GOMES FERREIRA, M. G. }\end{array}$ & $\begin{array}{l}\text { Universidade } \\
\text { Federal do } \\
\text { Paraná }\end{array}$ \\
\hline $10^{a}$ & $\begin{array}{l}\text { Design para Experiência e } \\
\text { Customização em Massa }\end{array}$ & $\begin{array}{l}\text { Design para experiência, } \\
\text { Design de Sistemas } \\
\text { Produto/Serviço, } \\
\text { Customização em Massa. }\end{array}$ & $\begin{array}{l}\text { SALES, R.; } \\
\text { RIOS, I. G. T. }\end{array}$ & $\begin{array}{l}\text { Universidade } \\
\text { do Estado de } \\
\text { Minas Gerais }\end{array}$ \\
\hline $10^{\mathrm{a}}$ & $\begin{array}{l}\text { Análise preliminar de } \\
\text { sistema de produto-serviço } \\
\text { para estofados em Arapiraca } \\
(\mathrm{AL}) \text { : estudo de caso }\end{array}$ & $\begin{array}{l}\text { Design para sustentabilidade; } \\
\text { Sistema de produto-serviço; } \\
\text { Móveis-estofados }\end{array}$ & $\begin{array}{l}\text { RAPOSO, A.; } \\
\text { CESAR, S. F.; } \\
\text { KIPERSTOCK, A. }\end{array}$ & $\begin{array}{l}\text { Universidade } \\
\text { Federal da } \\
\text { Bahia }\end{array}$ \\
\hline 9aa & $\begin{array}{l}\text { Design de moda sustentável: } \\
\text { uma proposta de sistema } \\
\text { produto-serviço a partir de } \\
\text { peças originadas de brechós }\end{array}$ & $\begin{array}{l}\text { Sustentabilidade; produtos de } \\
\text { moda; Sistema produto- } \\
\text { serviço; Brechós }\end{array}$ & $\begin{array}{l}\text { MARTINS, S.; } \\
\text { BUSSO, V. }\end{array}$ & $\begin{array}{l}\text { Universidade } \\
\text { Federal do } \\
\text { Paraná }\end{array}$ \\
\hline 9ạ & $\begin{array}{l}\text { Coleta de água de chuva: } \\
\text { identificação de } \\
\text { oportunidades de inovação } \\
\text { através do Design }\end{array}$ & $\begin{array}{l}\text { Sistema Produto Serviço; } \\
\text { Água de chuva }\end{array}$ & $\begin{array}{l}\text { SANTOS, A.; PEREIRA, J. } \\
\text { V. I.; ZACAR, C. R. H.; } \\
\text { COSTA JR, J. ; DE JESUS, } \\
\text { V.; ENRICONI, A. }\end{array}$ & $\begin{array}{l}\text { Universidade } \\
\text { Federal do } \\
\text { Paraná }\end{array}$ \\
\hline 9ạ & $\begin{array}{l}\text { Design para a } \\
\text { Sustentabilidade: Sistemas } \\
\text { de separação, coleta e } \\
\text { destinação de resíduos } \\
\text { domiciliares em condomínios } \\
\text { horizontais }\end{array}$ & $\begin{array}{l}\text { Design para a } \\
\text { sustentabilidade; Sistemas } \\
\text { produto-serviço; Resíduos }\end{array}$ & $\begin{array}{l}\text { ALBACH, D.; } \\
\text { PEREIRA, C. }\end{array}$ & $\begin{array}{l}\text { Universidade } \\
\text { Positivo - } \\
\text { Curitiba PR }\end{array}$ \\
\hline 9ạ & $\begin{array}{l}\text { O Design aplicado à } \\
\text { qualificação do sistema de } \\
\text { transporte público em Porto } \\
\text { Alegre }\end{array}$ & $\begin{array}{l}\text { Design estratégico; Sistema- } \\
\text { produto; Paradas de ônibus }\end{array}$ & $\begin{array}{l}\text { TRAMONTINA, H. J.; } \\
\text { TAROUCO, F.F. }\end{array}$ & $\begin{array}{l}\text { Universidade } \\
\text { do Vale do } \\
\text { Rio dos Sinos }\end{array}$ \\
\hline
\end{tabular}

Fonte: Os autores

Este processo possibilitou comparar o teor das publicações com os eixos conceituais de SPS descritos anteriormente, trazendo um panorama a respeito de por onde transita o tema nas últimas quatro edições do P\&D Design.

Dos nove artigos levantados, seis mostram maior aderência ao eixo conceitual de SPS relacionado à temas como engenharia de produção, redução de impactos, otimização de processos e sustentabilidade (GOEDKOOP et al, 1999; MONT, 2001; BAINES et al, 2007, TUKKER; TISCHNER, 2006). Fazem parte desta divisão os artigos de ARRUDA, A; ARRUDA, F. (2012), SALES, R.; RIOS, I. 
(2012), RAPOSO, A. et al (2012), MARTINS, S.; BUSSO, V. (2010), SANTOS, A. et al (2010), e ALBACH, D; PEREIRA, C. (2010).

Pela linha da sustentabilidade, o artigo Lixo sustentável: uma proposta de SPS para coleta do lixo urbano, de Arruda \& Arruda (2012) apresenta uma proposta de implementação de um sistema para coleta de resíduos residenciais, aplicando embasamentos teóricos relacionados ao SPS e à metodologia projetual do Design de Produto. No mesmo caminho está o artigo Design para a Sustentabilidade: Sistemas de separação, coleta e destinação de resíduos domiciliares em condomínios horizontais, de Albach \& Pereira (2010), que apresenta os resultados de uma metodologia de exploração do SPS no contexto do design sustentável.

Também pela linha da sustentabilidade, mas como um olhar nos aspectos de inovação pela redução de impactos, o artigo Coleta de água de chuva: identificação de oportunidades de inovação através do Design, de Santos et al (2010), que tem por objetivo o desenvolvimento de um SPS para coleta de água pluvial em habitações de interesse social, apresentando, para isso, o caso do Projeto Amana.

Pelo viés da otimização de processos, o artigo Design para Experiência e Customização em Massa, de Sales \& Rios (2012) analisa os conceitos de Design para a Experiência, propondo uma relação entre esta atividade e os novos sistemas de produção industriais baseados na customização em massa e nas tecnologias de manufatura rápida. Já o artigo Análise preliminar de sistema de produto-serviço para estofados em Arapiraca (AL): Estudo de caso, de Raposo et al (2012) traz reflexões sobre um SPS para estofados. A publicação de Martins \& Busso (2010), Design de moda sustentável: uma proposta de sistema produto-serviço a partir de peças originadas de brechós, discute a proposta conceitual de um sistema para desenvolvimento de coleção de produtos de moda respeitando um ciclo de produção sustentável.

Já os artigos de HIRANO, C.; COSTA, F.C.X. (2016), FONTANA, I. et al (2012) e TRAMONTINA, H.; TAROUCO, F. (2010) estão mais alinhados com a abordagem estratégica e focada na entrega de significados. (MANZINI; VEZZOLI, 2002; MERONI, 2008; TUKKER, 2003; ZURLO, 2010; CELASCHI; DESERTI, 2007).

No artigo A Colaboração no Nível Estratégico como Facilitador no Design de Sistemas Produto-Serviço, de Fontana et al (2012), o objetivo é esclarecer como a colaboração no nível estratégico do design pode facilitar o processo de concepção de um SPS. Da mesma forma, Hirano \& Costa (2016) discutem em seu Perfil de concerns e projeto de sistemas produtos-serviços na gastronomia: uma discussão metodológica de que forma a análise dos concerns - disposições e padrões que as pessoas trazem para o processo emocional sobre um determinado estímulo - dos usuários de uma operação gastronômica pode contribuir para o desenvolvimento de um SPS. Já Tramontina e Tarouco (2010) focam em seu O Design aplicado à qualificação do sistema de transporte público em Porto Alegre como uma proposta estratégica de SPS estaria adequada para melhorar o sistema de transporte público urbano de uma capital.

Diante de uma produção acadêmica quantitativamente modesta, seria imprudente sugerir que o entendimento do SPS está mais atrelado a um ou outro viés. Ou, ainda, que a disseminação de conteúdo sobre Design de SPS esteja melhor estruturada em bases ligadas aos aspectos de redução de impactos, otimização de processos e sustentabilidade. Possivelmente esta tendência seja reflexo de um direcionador global, que vem imprimindo de maneira ampla nas organizações a necessidade de um posicionamento coerente com estas questões específicas. Confirmamos isso ao 
reconhecermos a recente criação de redes de instituições, como a LenS - Learning Network on Sustainability - que estão engajadas na formação de uma nova geração de designers capazes de desenvolver soluções inovadoras para uma sociedade mais sustentável.

\section{Considerações finais}

É sabido que as primeiras publicações nacionais sobre o tema datam de 2006 e 2007, no Congresso Internacional de Pesquisa em Design - P\&D/2006 e no I International Symposium on Sustainable Design - ISSD/2007. Doze anos depois, verificamos nesta pesquisa que o P\&D Design publicou menos de 0,5\% do seu total em artigos relacionados ao tema SPS em seus anais, entre 2010 e 2016. Embora existam no país outros eventos com foco mais específico e que tratam este tema com maior profundidade, como é o caso do International Seminar on Sustainable ProductService Systems and Distributed Economy, é consternador apurar que este assunto não tenha representatividade no mais tradicional evento brasileiro de pesquisa em Design. Esta situação é analisada por Vezzoli et al (2018), que observam o seguinte:

O problema da relativa baixa presença do ensino e pesquisa acerca de Sistemas Produto+Serviço no Brasil está ligado, em parte, ao baixo volume de pesquisadores doutores com formação no tema e a insuficiência de material didático para suporte ao ensino. (VEZZOLI et al, 2018, p.171).

Estes mesmos autores traçam a relação direta entre academia e mercado. Se as instituições de ensino não preparam adequadamente os profissionais para atuarem no Design de SPS, nossas organizações seguirão incompetentes na elaboração de SPS mais qualificados. Logo, a contribuição acadêmica é fundamental neste sentido. Entendendo sua importância como sendo uma das principais contribuições do vetor estratégico do design, sugerimos uma agenda para debate e maior aprofundamento do tema no campo do Design.

Esperamos que esta análise da produção sobre Design de SPS indique a oportunidade latente de desenvolvimento de estudos nesse campo, e que, diante de tantas possibilidades que isso traz, provoque maior interesse pela área, principalmente dentro do campo de pesquisa do Design. Recomendamos, ainda, a continuidade e a ampliação desta pesquisa a partir da análise de outras edições deste mesmo congresso.

\section{Referências}

BAINES, Tim.; LIGHTFOOT, Howard; EVANS, Steve; et al. State-of-the-art of product servicesystems. Proc IMechE, v.221, Part B: J Engineering Manufacture, p.1-10, 2007.

CELASCHI, Flaviano; DESERTI, Alessandro. Design e innovazione: strumenti e pratiche per la ricerca applicata. Roma: Ed. Carocci, 2007.

COSTA, Nina; PATRICIO, Lia; MORELLI, Nicola; MAGEE, Christopher. Bringing service design to manufacturing companies: Integrating PSS and Service Design approaches. Design Studies 55, 2018, p.112-145

GOEDKOOP, Mark; VAN HALEN, Cees; RIELE, Harry; ROMMENS, Peter. Product service system: 
ecological and economic basics. Technical Report. Storrm, C.C., 1999.

KHAN, K. S.; KUNZ, R; KLEIJNEN, J; ANTES, G. Five steps to conducting a systematic review. Journal of the royal society of medicine. UK: Vol 96. pg 118-121. 2003.

KRIPPENDORFF, Klaus. The Semantic Turn: a New Foundation for Design. New York: Taylor\&Francis, 2005.

MANZINI, Ezio. Artefatti: verso una nuova ecologia dell'ambiente artificiale. Milão: Ed. Domus Academy, 192p. 1990.

MANZINI, Ezio; VEZZOLI, Carlo. Product-service systems and sustainability: opportunities for sustainable solutions. United Nations Environment Program (UNEP) Paris: Division of technology industry and economics, Production and consumption branch.18p. 2002.

MERONI, Anna. Strategic design: where are we now? reflection around the foundations of a recent discipline. Strategic design research journal 1 (1), Unisinos, 2008, p.31-38.

MONT, Oksana. Clarifying the concept of product-service system. Journal of Cleaner Production. v.10, p.237-245, 2001.

MORELLI, Nicola. Product-service systems, a perspective shift for designers: a case study: the design of a telecentre. Design Studies, v.24, p.73-99, 2003.

PARASURAMAN, A.; ZEITHAML, Valarie; BERRY, Leonard. A conceptual model of service quality and its implications for future research. Journal of Marketing, v.49, p.41-50, 1985.

SASSANELLI, Claudio; PEZZOTTA, Giuditta; ROSSI, Monica; TERZI, Sergio; CAVALIERI, Sergio. Towards a lean product service systems (PSS) design: state of the art, opportunities and challenges. Procedia CIRP 30, p.191-196, 2015.

TUKKER, Arnold. Eight types of product-service systems: eight ways to sustainability? Conference paper. 11th International Conference of Greening of Industry Network / Innovating for Sustainability. San Francisco, 2003.

TUKKER, Arnold; TISCHNER, Ursula. Product-services as a research field: past, present and future. Reflections from a decade of research, Journal of Clean Production. v.14, p. 1552-1556, 2006.

UNIVERSIDADE FEDERAL DO PARANÁ. Objetivos do programa de pós-graduação em design. Disponível em http://www.sacod.ufpr.br/portal/ppgdesign/apresentacao/objetivos. Acesso em 20 de março de 2018.

UNIVERSIDADE DO VALE DO RIO DOS SINOS. Apresentação do programa de pós-graduação em design. Disponível em http://www.unisinos.br/mestrado-e-doutorado/design/presencial/portoalegre. Acesso em 20 de março de 2018.

VEZZOLI, Carlo. Sistema produto + serviço sustentável: fundamentos. Curitiba: Ed Insight, 2018.

VEZZOLI, Carlo; SANTOS, A.; CHAVES, L.; CASTILLO, L. A.; GOMEZ, C. R.; LEPRE, P. R.; ENGLER, R. C.; MARTINS, S. B.; FIGUEIREDO, L. F. SPSS e DE no contexto nacional e internacional. in: VEZZOLI, Carlo. Sistema produto + serviço sustentável: fundamentos. Curitiba: Ed Insight, 2018.

ZURLO, Francesco. Design Strategico. in XXI Secolo, v.4, Gli spazi e le arti. Roma: Enciclopedia Treccani, 2010. 